\title{
DECLARACIONES DE CAUTIVOS: PIEZAS DE ARCHIVO MULTIVOCALES DE LA FRONTERA COLONIAL (VIRREINATO DEL RÍO DE LA PLATA, SIGLO XVIII)*
}

\author{
CAPTIVES'DECLARATIONS: MULTI-VOCAL ARCHIVAL PIECES \\ IN THE COLONIAL FRONTIER (VICEROYALTY OF THE RÍO \\ DE LA PLATA, 18TH CENTURY)
}

Lidia Rosa Nacuzzi ${ }^{* *}$ y Carina Paula Lucaioli ${ }^{* *}$

\begin{abstract}
Consideramos aquí unas piezas documentales particulares como las declaraciones de cautivos tomadas en las fronteras por funcionarios coloniales. Los declarantes eran personas que habían sido cautivadas por grupos indígenas en malones u otras acciones violentas o, también, algunos que habían decidido escapar de los poblados coloniales para buscar una vida más libre. Evaluamos especialmente el formato pautado de estos documentos, los diversos actores que logramos identificar como autores ocultos de esos escritos, el contenido en cuanto a los datos etnográficos y las situaciones precisas de su producción.

Palabras claves: archivo, crítica de fuentes, etnohistoria, grupos indígenas.

Certain documentary pieces are taken into consideration here, like the captives' declarations obtained by frontier colonial officials. The people who declared had been captured by indigenous groups in their raids (malones) or during other type of minor violent actions; there were also those who had decided to escape from the colonial towns seeking a life with more freedom. Thus, we evaluate the given format of these documents, the different actors identifiable as hidden authors of these papers; and regarding content, the ethnographical data and the specific situations of their production.
\end{abstract}

Key Words: archive, source criticism, Ethnohistory, indigenous groups.

\section{Introducción}

El estudio de los grupos indígenas durante el período colonial americano constituye una tarea que apela a la paciencia del artesano para reconstruir momentos históricos e identificar datos etnográficos a partir de los discursos generados por otros. Los grupos indígenas y los colonizadores establecieron variadas formas de interrelación en los distintos ámbitos de frontera, generando un espacio mestizo de mutuo conocimiento cuya administración ocupaba un lugar central en la agenda de la monarquía española y sus funcionarios de distintos rangos. Desde esas fronteras, y para su gobierno, se produjeron numerosos testimonios administrativos, personales y científicos que hoy conforman la base documental que permite estudiar la historia de los grupos indígenas de la región. También, desde los primeros contactos interétnicos se conformó un imaginario particular sobre los espacios de frontera, entendidos como parajes lejanos, marginales y diferenciados de otros lugares ocupados por las ciudades; como tierras libres o regiones inhabitadas -en una tendencia reiterada por negar la presencia de poblaciones nativas-; como ámbitos en donde ocurrieron relaciones interétnicas, mestizajes, intercambios simbólicos, complementariedad y competencia por los recursos, y donde se crearon mecanismos -como los tratados de paz, los indios amigos, las misiones, guardias y fuertes- para el reconocimiento, ocupación, control y defensa del territorio (Nacuzzi y Lucaioli 2014).

La documentación que hoy constituye la principal fuente para los estudios de Antropología histórica se produjo desde los ámbitos públicos y privados y luego, ya sea por azar o por su valor histórico, fue incorporada al conjunto de documentos preservados en algún repositorio regional,

\footnotetext{
* Resultado Proyecto PIP CONICET No 112-201101-00641.

** Consejo Nacional de Investigaciones Científicas y Técnicas (CONICET). Universidad de Buenos Aires, Argentina. Correos electrónicos: lidianacuzzi@conicet.gov.ar; carinalucaioli@conicet.gov.ar
} 
nacional o internacional. Puesto que todo discurso conlleva determinados puntos de vista, estas fuentes de archivo no son portadoras de una verdad intrínseca ni objetiva, su fuerza explicativa reside en que constituyen piezas y retazos -incompletos e inconexos-del quehacer humano (Nacuzzi 2002) y en que son portadores de indicios y significados que el investigador se aboca a descifrar para obtener datos para su investigación (Ginzburg 2004). En este sentido, reconstruir la historia de los grupos indígenas del siglo XVIII es tan complejo como fascinante. Es desalentador reconocer que los datos provienen casi con exclusividad del discurso colonial, un discurso heterogéneo que, por medio de la voz de sus múltiples representantes, impuso diversas etiquetas y prejuicios sobre los pueblos nativos que se pretende estudiar. Solo en contadas ocasiones se encuentra un documento de factura indígena y, cuando esto ocurre, no deja de imponerse el tamiz colonial, presente desde el momento en que se echó mano del recurso de la escritura en sociedades ágrafas (Godoy 2003).

En el plano del lenguaje y la interpretación del discurso es donde se nos plantean los mayores desafíos a la hora de interrogar y valorar un determinado documento. Antropólogos e historiadores hemos desarrollado y aplicado numerosas herramientas metodológicas para desmantelar los documentos históricos en busca de los datos que nos permiten avanzar en las respuestas a nuestros problemas de investigación. A menudo nos encontramos con relatos que se contradicen entre sí, con hilos narrativos que se interrumpen sin previo aviso, con largos silencios o con ausencia de datos específicos sobre la problemática que nos interesa. En este sentido, nuestros mayores esfuerzos metodológicos están orientados a detectar en los escritos, las miradas y los sesgos impuestos por quienes participaron del proceso de escritura y de su entorno histórico-cultural. Nacuzzi (2002) propuso identificar y considerar para el análisis de los datos de las fuentes documentales los diversos contextos -cultural, de las situaciones sociales, de enunciación, del campo del discurso, entre otros-en los que se inserta un escrito. Reconstruir cada uno de estos contextos implica resituar aquello que ha sido dicho en el pasado con las circunstancias de producción del documento que hoy se conserva en algún archivo histórico, atendiendo a sus distintos niveles: el de las acciones, el de los discursos y el de los imaginarios. Ninguno de ellos puede ser interpretado escindido de los demás, puesto que es en el interjuego de los actos, las palabras y las ideas donde la historia recobra sus sentidos.

Atendiendo a esos condicionamientos, en esta contribución nos hemos propuesto focalizar en un tipo de documento, aquel que buscó registrar por medio de un formato escrito una enunciación propia de la oralidad; es decir, transformó un registro discursivo oral -con entonaciones, giros idiomáticos y recursos discursivos muy personales-en uno escrito, fijado por las formas gramaticales y de redacción de la época. Analizaremos, entonces, aquellos papeles que se caracterizan por incluir declaraciones personales, como fueron los testimonios tomados a los cautivos ${ }^{1}$ de los indígenas en su regreso a la jurisdicción colonial, testimonios que luego sirvieron a los funcionarios a cargo de las políticas fronterizas y de la administración colonial en general para el conocimiento de lo que se conocía como la "tierra adentro" y el establecimiento de relaciones políticas con los grupos indígenas no sometidos. Recurriremos a ejemplos del corpus documental acerca de los grupos indígenas cazadores recolectores de la Pampa, la Patagonia y el Chaco durante el siglo XVIII.

\section{Los Documentos y sus Contextos}

Cada documento refleja de manera implícita la incidencia del contexto social en el que fue enunciado en tanto se inscribe en un determinado momento histórico y político de los espacios de frontera y las situaciones de contacto entre el mundo indígena y la colonia. Responden, de manera general, a la agenda de conquista y dominación de la corona española en América, influida por el imaginario de superioridad/inferioridad étnica con que el Viejo Mundo conceptualizaba a sus colonias. Entre otros condicionantes se inscriben también en un momento donde el público europeo reclamaba cierto tipo de información sobre aquellas geografías lejanas y desconocidas, que tendía al registro de lo exótico y la exageración de las diferencias al mismo tiempo que se consolidaba el interés naturalista guiado por el paradigma científico del iluminismo. Considerando el ámbito de la administración virreinal, el tipo de información que se consignaba por escrito variaba en función de la posición geopolítica respecto de los centros administrativos y de la atención que suscitaba, la disponibilidad, obtención y distribución de los recursos económicos, las formas en que se entablaron las relaciones interétnicas con los numerosos grupos 
nativos y los imaginarios construidos en torno a este espacio y sus habitantes. En la minucia de lo cotidiano las cuestiones administrativas o ejecutivas impusieron formatos de escritura específicos según se tratara de correspondencia entre funcionarios, cartas anuas, informes, autos, actas de cabildos, probanzas de mérito, testimonios judiciales, declaraciones de cautivos, etc. Finalmente, los discursos se impregnaron de las subjetividades, criterios, formas discursivas, modismos, intenciones y caligrafía de los autores y escribientes de esos papeles. En términos generales, estos aspectos -y muchos otros- guían la interpretación del corpus con el que trabajamos. No obstante, cada pieza documental requiere un análisis específico que considere el formato del documento, la identificación de los autores, la valoración del contenido explícito e implícito en el discurso escrito $\mathrm{y}$, por último, el contexto específico de la acción en la cual fue generado.

Cuando hablamos del formato de un documento nos estamos refiriendo a sus características formales con relación a la presentación de la información y el contenido del relato. Los documentos del ámbito público conllevan reglas protocolares más o menos estrictas sobre cómo debe volcarse la información; algunos repiten un mismo modelo a lo largo del tiempo y en distintas jurisdicciones -como las actas de cabildos y las probanzas de mérito- mientras que otros -como la correspondencia personal entre funcionarios del Estado-pueden variar enormemente según la intencionalidad del escrito ${ }^{2}$. En el caso de las declaraciones consideradas aquí, se corresponden a lo que Oesterreicher (1997) identifica como una transposición de lo hablado a lo escrito, que se caracteriza por recoger con la máxima fidelidad lo expresado por los declarantes.

La identificación de los autores -cuyas voces se cuelan de manera explícita o velada en cada documento- es otro de los aspectos a considerar frente a la interpretación de un documento escrito. Conocer quién o quiénes dijeron lo que se registró permite otorgarles a las palabras una intencionalidad no necesariamente incluida en el contenido gramatical. La autoría puede corresponder a personas físicas pertenecientes al amplio abanico de agentes coloniales o a una institución u organización como los cabildos o las agrupaciones religiosas. En líneas generales, la identidad del que enuncia condiciona la interpretación del discurso en dos momentos: la que realiza el destinatario para el que fue enunciado -con sus implicancias en el plano de las acciones y las prácticas sociales- y la que luego elabora del historiador que analiza la dupla autor-destinatario y construye sus datos de investigación.

Un escrito se vuelve relevante en función de su contenido, es allí donde se inicia la relación entre el investigador y sus documentos. Si bien el formato y el autor-destinatario delinean en parte el contenido, el cuerpo del manuscrito es único y original. Los temas aludidos, el grado de detalle y extensión, la forma narrativa y la calidad gramatical le otorgan sentidos diversos. Por otra parte, el contenido no se limita a lo explícito; ciertos indicios del escrito dan cuenta de omisiones, agregados, tergiversaciones y silencios que modifican -intencionalmente o no- la información registrada.

Mediante el contexto específico de la acción hacemos referencia a las situaciones sociales precisas en las que se inserta la producción de un escrito. Todo relato se inscribe en el interjuego de diversas relaciones de poder que indican lo que se puede y lo que no se puede decir, distinguen lo correcto de lo incorrecto y habilitan ciertas formas discursivas por sobre otras. Nuestra mirada analítica contempla la ponderación de los documentos según esos aspectos y considera las acciones que promueve, atendiendo a la distancia entre el discurso escrito y las prácticas sociales.

Todas estas circunstancias que participan del documento -y que solo se pueden separar con fines analíticos- ponen en evidencia que aquello que nos llega como un discurso acabado, homogéneo y unívoco, resulta de la componenda de una multiplicidad de voces, intereses e intenciones.

\section{Las Declaraciones de Cautivos}

Desde la bibliografía especializada se han producido numerosos trabajos que analizan, en el contexto de la vida en las fronteras, las problemáticas asociadas a la circulación de los cautivos entre los grupos indígenas $-\mathrm{y}$, en menor medida, entre los hispanocriollos- y sus implicancias sociales, económicas, políticas y simbólicas ${ }^{3}$. También se han utilizado las declaraciones de cautivos como fuentes insustituibles de datos para el estudio de los grupos indígenas no sometidos. Así, en las fronteras o márgenes de la colonia, ellos ofrecieron testimonios sobre sus vivencias tierra adentro que hoy contribuyen al estudio de esos grupos subalternos de la historia colonial. No obstante, aún no se han analizado lo suficiente algunas particularidades 
que posee el corpus documental producido a expensas de estos personajes marginales o de bajo estatus social y sobre los múltiples indicios -"los datos marginales, considerados como reveladores" (Ginzburg 2004: 78)- que nos brindan esos escritos. Este trabajo constituye una reflexión sobre esa triple marginalidad que converge en las declaraciones del tipo que estamos analizando: la de los cautivos, la de las fronteras y la de los datos velados y secundarios.

\section{El foco puesto en el formato}

El tipo de documentos que en su interior reproduce una declaración tomada a un tercero en el marco de una acción avalada y reconocida por el estado colonial, se caracteriza por el hecho de transmitir una experiencia que se registra con ciertas formalidades. En los testimonios tomados a los cautivos que regresan de tierra adentro, se pretendía mantener la fidelidad de los datos que brindaban los testigos, debido a que esa información se reunía con fines muy precisos -aunque no aparecen explícitos- y serviría para la toma de futuras decisiones. Estas declaraciones brindaban información sobre el territorio, los grupos indígenas, sus movimientos y alianzas políticas y permitían planificar acciones militares o acuerdos diplomáticos.

Los testimonios se recababan siguiendo un protocolo preestablecido que consistía en la lectura de ciertas preguntas al declarante; las mismas pueden considerarse rígidas aunque, al incorporar una experiencia personal involucran "vestigios de la lengua espontánea" que rompen con la formalidad discursiva (Maldonado 2011:138). En este sentido, los testimonios de cautivos presentan cierto cariz de espontaneidad basado en un discurso de aspecto improvisado. Contribuye a esa apariencia la escasa formalización de los interrogatorios, la falta de datos de filiación sobre los declarantes, su calidad de iletrados y la situación de frontera en la que se registraban, además de no haberse conservado como un corpus particular y estar desperdigados en legajos de diferentes centros administrativos del período colonial. Sin embargo, una mirada atenta sobre esos testimonios permite identificar rápidamente algunas regularidades.

Por ejemplo, para el siglo XVIII en la frontera sur de Buenos Aires cuando un cautivo se acercaba a alguno de los fortines coloniales huyendo de sus ocasionales captores, se le solicitaba de inmediato que prestara declaración sobre su experiencia tierra adentro ante el jefe de frontera más cercano, para luego ser remitido él mismo junto con esa declaración a las autoridades superiores; esto nos deja en claro que la información brindada y la propia persona del declarante eran considerados cuestión de Estado. El contenido de estas declaraciones muestra cierta regularidad impuesta por el formato y las preguntas formuladas en los interrogatorios, a veces de manera implícita y otras más evidentes. Una fórmula sintética de interrogatorio contemplaba haber "Preguntado de qué paraje se huyó, de qué toldería, y el designio que traían los indios"; "Preguntado si los españoles podrán llegar al paraje donde paran estos indios"4; "cómo se llama, de dónde es natural, cómo le cautivaron los indios, qué número de ellos sería, de qué naciones, qué caciques venían y qué preguntas le hicieron"5. En otras ocasiones se requerían más detalles: "si sabe estos indios tienen trato con alguna población española", "si sabe estos indios tienen guerra con otros de otra nación"6.

En estos interrogantes es posible identificar también las cuestiones relevantes sobre las que los funcionarios querían conocer más: los nombres de caciques, los parajes de ubicación de las tolderías, la cantidad de individuos y jefes que había en ellas -o sea la cantidad de lanzas o poder bélico-, las distancias recorridas en la fuga $-y$ por ende las distancias entre las tolderías y los puestos de guardia-, las aguadas del camino y, en general, la situación político-estratégica que se deducía de los movimientos de los grupos indígenas respecto de la frontera: hacia dónde iban cuando se alejaban de ella, por dónde entrarían o atacarían desde sus toldos y territorios, qué alianzas con otros grupos se evidenciaban, entre otras.

En el contexto de las fronteras del Chaco, para el mismo período fue producida una serie de documentos relativos a las negociaciones de paz con algunos caciques mocovíes. En ellas adquirió especial protagonismo Rafael Holmos, un excautivo de los indígenas convocado desde la Gobernación del Tucumán como conocedor de esos territorios para que se trasladara hacia tierra adentro y estableciera contacto con cinco caciques a los que debía conducir a la reducción de la Concepción. A su regreso se le tomó declaración sobre: "de qué número se componen éstas [agrupaciones], a qué distancia se hallan de esta reducción, qué países ocupan y qué ríos se encuentran hasta llegar a ellos"; también debía informar sobre la distancia recorrida y el tiempo 
insumido en el viaje ${ }^{7}$. Se deduce de las preguntas realizadas tanto en el ámbito chaqueño como en el de la Pampa, el aún insuficiente conocimiento que se tenía sobre estas geografías y los grupos nativos que la habitaban.

Hacia 1787, entre otras instrucciones y providencia relativas a las expediciones a Salinas -que eran viajes anuales que organizaba el Cabildo de la ciudad de Buenos Aires para la recolección de sal en la frontera sur y que involucraba el desplazamiento de una gran cantidad de vecinos, carretas, animales $\mathrm{y}$ tropa- encontramos unas instrucciones que indican que se habían formalizado las preguntas a realizar:

Interrogatorio para cuando hubiese de tomarse declaración a indio o cautivo

¿Dónde había sido aprehendido o cautivado, y a qué paraje lo llevaron?

¿Cuánto tardó en su venida y cómo la logró?

¿Qué indios estaban unidos[,] número de toldos y gente de pelea?

¿Qué caciques ha conocido, dónde están situados[,] número de toldos de cada uno, qué gente juntarán entre todos y si tenían baqueanos cristianos[,] de dónde son?

Si trataban de invadir la frontera y qué caballada tienen.

Sobre estos principios se continuará según lo que produzcan las respuestas ${ }^{8}$.

Así, la espontaneidad ficticia mencionada en los primeros ejemplos gira hacia una formalización más terminante que da cuenta de un mayor control del Estado sobre estos personajes y, también, de la regulación de la práctica del interrogatorio en los puestos de frontera. ${ }^{9}$ Analizando el encabezamiento, la lista de preguntas y la calidad de las respuestas, se hace evidente que en muchas ocasiones los escribientes y funcionarios pueden haber influido en las declaraciones completando algunos datos faltantes para los ítems requeridos, dejando una huella no siempre reconocible en el contenido del documento

En este sentido, se hacen patentes las dudas que nos suscitan algunas respuestas demasiado específicas acerca de rumbos, nombres, distancias, alianzas interétnicas y manejo de cautivos. Estimamos dificultoso que la mayoría de los cautivos conocieran los accidentes del camino con sus nombres, las distancias recorridas en leguas y los nombres de cada cacique y sus parientes con tanto detalle. Sobre todo, considerando que no todos eran baqueanos ni tenían experiencia respecto de la geografía y los pueblos indígenas; se trataba de personas capturadas durante incursiones violentas de los indios (malones), que vivían en pueblos coloniales o chacras, sin información específica sobre los caciques y sus parientes. Otro tipo de cautivo -acaso mejor informado sobre algunas de estas cuestiones- podía ser algún soldado o presidiario que huía por decisión propia de los fuertes o poblados a vivir en las tolderías y regresaba en un período corto. Ambos desconocían las lenguas indígenas en uso en la región y, sin embargo, algunos de sus testimonios resultaban un dechado de precisiones.

En otros casos, algunos cautivos permanecían durante años entre los grupos indígenas y, luego, por diversas razones regresaban a vivir con los hispanocriollos, como los casos de Rafael Holmos y Cristóbal de Almaraz ${ }^{10}$ para el espacio chaqueño o Santiago de Avendaño para el pampeano-patagónico $^{11}$. Así, el amplio conocimiento de la lengua y las redes sociales que habían fomentado en su estadía tierra adentro, podía ponerlos al servicio de la colonia para actuar como lenguaraz o mediador diplomático. En esos casos, las memorias transcritas de estos personajes presentan otras formas posibles de deformación de los datos, ya sea por el tiempo transcurrido entre los sucesos y su relato o por tergiversaciones intencionales sobre hechos que no resulta conveniente contar.

Las instrucciones formalizadas en un cuestionario cerrado como el que hemos citado, vienen a confirmar que pueden haberse forzado las respuestas para lograr cubrir todos los ítems requeridos $\mathrm{y}$, así, la lista de preguntas revierte gran parte de la fiabilidad de los datos y desmonta su pretensión etnográfica. Esta situación sucede aún sin considerar las posibles elaboraciones que los excautivos pueden haber preparado para esas respuestas conociendo la inminencia del interrogatorio que era habitual inquirir al regreso de tierra adentro. En este sentido, vale como ejemplo de que había un conocimiento previo acerca de las rutinas a seguir con el regreso -interrogatorio y envío del cautivo a la capital a disposición del virrey-, la apremiante insistencia que fue necesario desplegar con uno de los cautivos encontrado en las cercanías de la guardia de Chascomús, a la que solo concurrió amenazado de muerte ${ }^{12}$.

Como hemos visto, el formato propio de estos documentos ejerce ya una primera condición sobre el contenido del discurso, puesto que las preguntas 
-implícitas o explícitas- tienden a direccionar el testimonio hacia unos pocos temas centrales mientras que pueden silenciar u omitir otras partes del posible relato. Además, la aplicación de un cuestionario puede haber incitado la colaboración de otras voces que agregaron, completaron o corrigieron los datos del testigo, conformando documentos polifónicos no siempre reconocidos como tales.

\section{El foco puesto en los autores}

Las declaraciones de cautivos del tipo que aquí estamos analizando adelantan ya cierta información sobre los autores de esos discursos: se trata de diferentes miembros de la sociedad colonial que, por diversos motivos, fueron obligados a permanecer entre los grupos indígenas de tierra adentro ${ }^{13}$. No obstante, hemos adelantado que el formato de este tipo de documentos involucra implícitamente otras voces ajenas a la reconocida en términos formales como "testimonio" o "declaración", que supone la transcripción fiel de un relato unívoco basado en una experiencia personal del entrevistado. Bajo la ficción del testimonio aparecen datos que remiten a otras voces calificadas que complementan lo que se dijo. La lectura atenta de esos discursos permite pensar que los funcionarios que tomaban las declaraciones y los escribientes que las registraban aportaban al conjunto del relato, ya sea agregando o enmendando datos, jerarquizando la información por medio del ordenamiento en párrafos o bien imponiendo diversas formas de tergiversación asociadas a la acción de pasar el discurso oral a una versión escrita. Además, las diferencias ortográficas -sobre todo en los nombres de personas y lugares- o el uso incorrecto de los signos de puntuación pueden transformar el sentido de lo dicho. Por lo tanto, la contextualización de un documento de este tipo debería involucrar estos dos aspectos -uno explícito, el otro oculto- en cuanto a las voces implicadas en el relato.

En una declaración tomada a tres conocedores del Chaco se puede ver cómo un relato multivocal compuesto por tres personas distintas - posiblemente con distintos conocimientos y disímiles respuestasse construye como una unidad discursiva, en la cual no es posible distinguir el testimonio de cada uno. Dos de ellos son mencionados como "lenguaraces", Holmos y Mansilla, aunque sabemos por otro fragmento del mismo escrito que el primero era un excautivo, como también lo era Cardozo, mencionado en tercer término:
En esta dicha reducción a veinte y nueve días del expresado mes y año, en cumplimiento del auto antecedente [...] comparecieron con Rafael de Holmos, Juan de Mansilla, lenguaraces, los cuales habiendo dicho que Pablo Cardozo [...] era también práctico de los países del Chaco, a donde había estado cautivo muchos años, inteligente en sus lenguas se le mandó por SS comparecer y juntos los tres se les recibió ${ }^{14}$.

El cautivo que declara es la voz explícita del documento, es ella la que habitualmente ha llamado la atención de los investigadores por la calidad de sus datos etnográficos en tanto informante calificado y porque pone de manifiesto un tipo de intermediación cultural atractiva para el estudio de las relaciones interétnicas y los mestizajes. Si bien el formato propio de estas declaraciones oculta la multivocidad, la lectura atenta y relacional de un conjunto de documentos nos brinda ciertos indicios que harían posible identificarla, reforzando la idea de que "ningún documento tiene sentido en sí mismo" (Farge 1991: 73). El diálogo propuesto por el investigador entre distintos documentos producidos en torno a un acontecimiento -o una situación social particular, ubica a los testimonios de los cautivos en una red de datos y hechos históricos que los comprehende y complementa.

Así, aunque el relato se presenta como construido por un único autor -en tanto no se distingue "quién dijo qué"- se trata como señala Davis (2013) de una "construcción compuesta" por varios actores. En estos escritos aparecen identificados: el declarante, el o los testigos y el funcionario que toma la declaración; aunque sabemos que además participaban los escribientes, que son los personajes menos visibles y conocidos de la burocracia colonial. Sobre esas otras voces aún no se ha reflexionado lo suficiente.

Finalmente, nos interesa destacar que el funcionario que tomó la declaración y firma al pie del texto en cumplimiento de procedimientos institucionales repetidos y cotidianos, encarna también una acción política no del todo ingenua en tanto avala determinados discursos que serán incluidos como datos objetivos a tener en cuenta en el ámbito más general de las políticas del estado colonial. Una declaración de cautivo que daba cuenta de un peligro inminente podía servir para legitimar una solicitud de ayuda militar para la frontera implicada, por ejemplo. 
Teniendo en cuenta lo analizado hasta el momento, observamos que la forma habitual de citar estos documentos con el nombre del declarante como autor simplifica en extremo el proceso de producción y las múltiples voces implicadas en estos relatos.

\section{El foco puesto en el contenido}

Es el contenido lo que hace más o menos relevante a un documento y le otorga un carácter único como fuente de información para el historiador. El formato basado en preguntas y respuestas direcciona el discurso hacia ciertos ejes de interés clausurando otras variables, lo que predetermina el tipo de información registrada. A su vez, el carácter multivocal que hemos podido identificar inscribe al relato en el interjuego de una "comunicación asimétrica" (Oesterreicher 1997), en donde un declarante socialmente marginal se enfrentaba a un funcionario de rango medio que le tomaba declaración a una cantidad variable de testigos -vecinos reconocidos y letrados que podían firmar en su nombre- y a un escribiente encargado de registrar sus palabras. Así, el contenido del relato se inscribe en la tensión impuesta por las relaciones de poder preexistentes entre estos actores sociales y por el encorsetamiento del cuestionario que condicionaba tanto lo que se decía como lo que se registraba. El contenido de la declaración pasa un primer filtro en la elaboración que hace el declarante de los hechos -en función de lo que quiere contar a sus interlocutores-y una segunda instancia es tamizada por el funcionario y el escribiente quienes deciden sobre lo que finalmente quedará registrado. Hemos mencionado que el formato de estas declaraciones guiaba su contenido por medio de preguntas más o menos estereotipadas, aunque -para los funcionarios- dejaban abierta la posibilidad de improvisar en el interrogatorio bajo la fórmula "se procederá según lo que produzcan las respuestas". Así se definían los temas relevantes para la agencia colonial que insistía en recolectar cierto tipo de datos por sobre otros y, por medio de esas preguntas preestablecidas, unificaba el tipo de información obtenida de diversas fuentes y para distintos espacios de las fronteras.

Además, las declaraciones de los cautivos descansan en gran medida en la interpretación del que está siendo interrogado acerca de qué cree que se espera que responda. En este sentido, el contenido del relato es altamente subjetivo, a pesar de que luego esa información sea tomada como objetiva por el funcionario de mayor rango a la que va dirigida y, luego, por el historiador que la convierte en dato para el análisis. El interrogado recorta o sesga la información que posee en función de lo que cree que su interlocutor espera escuchar o según "lo que quería que los demás pensasen que él pensaba" (Carr 1987: 62 en Farge 1991: 73) y en función de sus intereses personales acerca de lo que está o no dispuesto a contar. Esto hace que en la componenda entre las expectativas del interrogador y del interrogado se explicite cierta información y se silencie otra. Por ejemplo, en el contexto en el que se desenvuelven estos encuentros encontramos ciertas cuestiones sistemáticamente silenciadas (Roulet 2004), como la cantidad de aguardiente que circulaba en el ámbito de las fronteras para los rescates de cautivos y los tratados de paz y, también, la vida privada y afectiva del cautivo en tierra adentro.

Otro aspecto a considerar se refiere al carácter de declaración jurada de estos interrogatorios, los que pretendían recolectar información verídica sobre tierra adentro. Los cautivos declaraban "por Dios nuestro señor y una señal de la cruz, bajo del cual prometieron decir verdad". ${ }^{15}$ Para los funcionarios de la administración colonial, esos testimonios veraces construían información objetiva sobre asuntos relativos a las relaciones con los grupos indígenas; sin embargo, los investigadores no tomamos tan a la ligera la fiabilidad de estos datos para elaborar argumentaciones históricas. Por sobre esa diferencia, ellos y nosotros valoramos las descripciones densas y muy elaboradas sobre distintos aspectos poco conocidos. En algunos casos, estas declaraciones hacen hincapié en el paisaje y la información geográfica:

caminando para la parte del norte como unos veinte días, regulando un día con otro a quince leguas por caminos llanos con muchas arboledas, abundantes de pastos, lagunas, pájaros y otros varios animales silvestres, llegaron al paraje nombrado la laguna El Dentudo (en nuestra lengua española) encontraron varios indios campeando en la cogida de animales silvestres para su mantenimiento ${ }^{16}$. 
En otros, se privilegian los datos de tipo etnográfico:

que los indios le aseguraron varias veces que los que habían entrado por el lado de Navarro a la choza eran Aucas, y Teguelchuz, y muchos más que los que allí venían, y que ellos eran rancacheles, y que con estos rancacheles venían siete caciques, y el Capitán Bravo que los gobernaba, y que cuando dieron la otra vez en este pago de Luján fueron cuatro indios pero ahora sí que venían muchos: que [...] dijese al Comandante de la Frontera de parte del Capitán Bravo, soltasen la india llamada Petrona, que tenía un hijo cautivo en poder de otros indios, y a un indio hermano del Capitán que se halla preso en Buenos Aires, que podrá llevarlos un cristiano sin recelo ninguno, y quedarían hechas las paces entre indios, y españoles, y que de lo contrario no habían de parar en hacer guerra a los cristianos ${ }^{17}$.

En este fragmento se encuentran datos sobre nombres de grupos étnicos, el nombre de un cacique, parentescos, mensajes para el comandante, intercambios de cautivos, malones y una propuesta de paz, todos ellos valiosos para programar las políticas de las fronteras y, también, para elaborar nuestras etnografías del pasado. En cambio, en otras ocasiones podemos hallar respuestas muy escuetas -"dice que no sabe lo que contiene la pregunta"- a preguntas muy elaboradas que, paradójicamente, son las que brindan mayor información al investigador:

Sean preguntados si saben, o han tenido noticia que la dicha ciudad de Santa Fe tiene comercio de maderas, cal, trigo, mulas y demás ganados, y el comercio corriente con los indios infieles pues todo lo que roban por otra ciudades van a vender en la dicha ciudad de Santa $\mathrm{Fe}^{18}$.

Como venimos señalando, el contenido, las voces implicadas y el formato se imbrican en cada una de las declaraciones de cautivos, esas piezas destacadas en la labor de reconstruir la historia de los grupos indígenas de las fronteras.

\section{El foco puesto en las situaciones sociales}

Estos documentos tienen en común que fueron producidos en la frontera, a la que entendemos como un ámbito de comunicación, interacción y mestizajes en donde se instalaron instituciones -fuertes y misiones- específicamente pensadas para el avance territorial y el control de las poblaciones indígenas (Nacuzzi y Lucaioli 2014). Cada fuerte, misión o ciudad en contacto con los grupos indígenas autónomos configuró formas de interacción particulares en donde descansa la singularidad de los distintos espacios de las fronteras. En el marco de esas coyunturas específicas cobran sentido cada una de las declaraciones tomadas a los cautivos. Así, el relato no puede ser comprendido de manera escindida a la situación social en la que fue generado y los motivos por los que fue registrado.

Ya hemos dicho que la información sobre tierra adentro y los grupos indígenas que la habitaban era una cuestión de Estado; la llegada de un cautivo iniciaba un protocolo de obtención de datos y registro de su declaración. En algunos casos, el contenido de esos relatos movilizaba la adopción de medidas urgentes para la defensa de las ciudades y los fuertes, la organización de entradas punitivas, el intercambio de cautivos y la concertación de acuerdos de paz. En todos los casos, la información se incorporaba al corpus de datos que circulaba entre los funcionarios y mediadores de los espacios de frontera sirviendo a corto y mediano plazo para guiar las políticas interétnicas en cuestiones diplomáticas y defensivas más generales.

A su vez, cada jefe de frontera aprovechaba el impacto que podía causar el tipo de información que debía elevar hacia esferas políticas de mayor jerarquía para insistir en la solicitud de refuerzos de soldados, armas, municiones, cabalgaduras y bastimentos. La precariedad y la falta de recursos de los enclaves de frontera constituían un problema reiterado que los funcionarios a cargo subsanaban solicitando ayuda a sus superiores, a las órdenes religiosas o a las redes indígenas con las que interactuaban asiduamente.

Las ciudades de las que dependían estos fuertes y misiones -que debían defenderlas de las incursiones indígenas- en ocasiones se hallaban igualmente desprovistas y frente al inminente peligro de sus fronteras tomaban acciones urgentes. Por ejemplo, en la ciudad de Santa Fe ante la 
posibilidad de un ataque indígena anticipado por el testimonio de un cautivo se ordenó alistar las embarcaciones menores y mayores para evacuar a las familias, mujeres, niños, religiosos y "todas las cosas sagradas", quedando en el poblado "la gente capaz de tomar armas" ${ }^{\prime 19}$.

En cuanto a las cuestiones geopolíticas que se dirimían en los espacios de frontera, tenían especial relevancia los tratados de paz y el establecimiento de relaciones interpersonales con los caciques amigos. Con vistas a estos objetivos, muchas de las preguntas que figuran en las declaraciones buscaban indagar sobre la predisposición de los caciques para establecer acuerdos:

dice que les ha oído decir a los indios aucas que si les niegan la paz a ellos y le hacen mal a Lepin que se unirán con los teguelchus, que asolarán las estancias de Buenos Aires y entrarán por cuatro o cinco partes asolando si posible es hasta la misma ciudad. Con el fin de acabar a toda la gente o que a ellos los acaben ${ }^{20}$.

De manera paralela a las negociaciones diplomáticas documentadas, se desenvolvían numerosas relaciones interpersonales, cotidianas y domésticas, cuyos protagonistas más visibles fueron los caciques y los jefes de frontera, pero que indudablemente involucraban otros personajes del ámbito de la toldería, del fuerte y de la misión en redes de interacción menos visibles pero reales, que impactaban directamente en el plano de las prácticas. Estos contextos sociales ocultos -difíciles de identificar y estudiar-complementan a aquellos otros más evidentes y mejor documentados. Tanto las redes sociales del ámbito público -reconocidas, institucionalizadas y formalizadas- como los vínculos establecidos entre personas concretas -con sus intereses, personalidades y afectos- convergen en el plano de las acciones y delinean los contextos situacionales en los que se desenvolvían las declaraciones.

\section{Consideraciones Finales}

Las declaraciones de cautivos, como cualquier otro escrito, son el resultado de un conjunto de condicionantes históricos, institucionales y burocráticos. Como investigadores preferimos este tipo de documentos en particular por su carácter testimonial y por la calidad etnográfica de los datos que nos ofrecen esos informantes calificados. A su vez, para la colonia la experiencia del cautiverio convertía a estos sujetos en voces autorizadas para entregar información estratégica sobre tierra adentro. Los funcionarios coloniales en aquellos momentos y los investigadores en la actualidad ponderamos esa información en función de otros saberes y supuestos compartidos. Saberes y supuestos que los investigadores denominaríamos "conocimiento no basado en fuentes" (Topolski 1982) y para los funcionarios coloniales constituía el "contexto cognoscitivo general" Oesterreicher (1997).

Al tratarse de un testimonio requerido en un contexto de procedimientos protocolares que incluyen preguntas, testigos, juramentos y rúbricas, se cristaliza la idea de que presenta información real y objetiva. A esa pátina de autenticidad se suma que su carácter nominal le brinda la apariencia de transmitir una única voz -la del declarante-. El análisis presentado aquí apunta a desmantelar esta simplificación puesto que hemos considerado las huellas del proceso de formulación de estos escritos (Oesterreicher 1997) que dan cuenta de las posibles distancias entre el acontecimiento vivido y lo relatado, entre ese relato y su registro escrito y, finalmente, entre ese escrito y nuestra interpretación como investigadores. Las distorsiones ocurridas en el desplazamiento de los dos primeros momentos son irrecuperables para el historiador, quien, sin embargo, puede afinar sus herramientas de análisis para resolver el del tercero.

Aquí hemos identificado la posibilidad de que otras voces se cuelen en el relato escrito -el funcionario que interroga, lenguaraces que traducen, escribientes que registran y testigos que avalan-y de que el contenido se haya visto adecuado por distintos filtros como la adición de datos, la censura o tergiversación de la información o la exaltación de ciertos aspectos. En el medio de estas cuestiones y enlazándolas, la fórmula del interrogatorio induce a adaptar, seleccionar, completar u omitir, imponiendo nuevos sesgos al relato y acallando su multivocidad.

\section{Agradecimientos}

A Laura Aylén Enrique, por la digitalización de documentos del Archivo General de la Nación (Argentina). 


\section{Referencias Citadas}

Areces, N., S. López y E. Regis

1992 Relaciones interétnicas en Santa Fe la Vieja: Rescate con charrúas. En Reflexiones sobre el V Centenario, editado por N. R. Areces, pp. 55-69. Facultad de Humanidades y Artes Editora (UNR), Rosario.

Ávila, L.

1994 Los cautivos en la frontera araucana. Revista Española de Antropología Americana 24: 191-207.

Carr, E. H.

1987 Qu'est-ce que l'histoire? Découverte, Paris, Francia.

Davis, N. Z.

2013 El historiador y los usos literarios. Revista Historia y Justicia 1: 1-7.

Farge, A.

1991 La Atracción del Archivo. Edicions Alfons el Magnànim. Institució Valenciana d'Estudis i Investigació, Alzira, España.

Ginzburg, C.

2004 Huellas. Raíces de un paradigma indiciario. En Tentativas, pp. 69-113 Prohistoria, Rosario.

Godoy, J.

2003 Cultura Escrita en Sociedades Tradicionales. Gedisa, Madrid, España.

Hux, M.

1999 Memorias del ex Cautivo Santiago de Avendaño. El elefante blanco, Buenos Aires.

Lucaioli, C. P.

2011 El poder de los cautivos: relaciones sociales entre abipones e hispanocriollos en las fronteras del Chaco austral (siglo XVIII). Nuevo Mundo Mundos Nuevos 11, Debates. http://nuevomundo.revues.org/62091 (20 octubre 2014).

Lucaioli C. P y S. H. Latini

2014 Fronteras permeables: circulación de cautivos en el espacio santafesino. Runa 35(1): 113-132.

Maldonado, S.

2011 Representaciones Sociales en Prácticas Discursivas de la Colonia. Facultad de Filosofía y Letras Universidad Nacional de Tucumán, San Miguel del Tucumán.

Mayo, C.

1985 El cautiverio y sus funciones en una sociedad de frontera. El caso de Buenos Aires (1750-1810). Revista de Indias XLV (175): 235-243.

Muzzopappa, E. y C. Villalta

2011 Los documentos como campo. Reflexiones teóricometodológicas sobre un enfoque etnográfico de archivos y documentos estatales. Revista Colombiana de Antropología 47 (1): 13-42.

Nacuzzi, Lidia R.

2002 Leyendo entre líneas: una eterna duda acerca de las certezas. En Historia y Estilos de Trabajo de Campo en la Argentina, editado por S. Visacovsky y R. Guber, pp. 229-262. Antropofagia, Buenos Aires.

2011 Los desertores de la expedición española a la costa patagónica de fines del siglo XVIII y la circulación de personas en los espacios de frontera, Mundo Nuevo, Nuevos Mundos. http://nuevomundo.revues.org/61394 (30 mayo 2011).

Nacuzzi, L. R. y C.P. Lucaioli

2014 Perspectivas antropológicas para el análisis histórico de las fronteras. En Pueblos Indígenas, Estados
Nacionales y Fronteras. Tensiones y Paradojas de los Procesos de Transición Contemporáneos en América Latina I, editado por H. Trinchero, L. Campos Muñoz y S. Valverde, pp. 27-72. Facultad de Filosofía y Letras (UBA), Buenos Aires.

Néspolo, E.

2008 Cautivos, ponchos y maíz. Trueque y compraventa, "doble coincidencia de necesidades" entre vecinos e indios en la frontera bonaerense. Los pagos de Luján en el siglo XVIII. Tefros 6(2). http://www.unrc.edu.ar/publicar/tefros/revista/ v6n $2 d 08$

Oesterreicher, W.

1997 Pragmática del discurso oral. Oralidad y Argentinidad. Estudios sobre la Función del Lenguaje Hablado en la Literatura Argentina editado por W. Berg y K. Markus Schäffauer, pp. 86-97. Gunter Narr Verlag Tübingen, Alemania.

Operé, F.

1997 Cautivos de los indios, cautivos de la literatura: El caso del Río de la Plata. Hispamérica 76/77: 49-75.

Ortelli, S.

1999 Historias de cautivos y agregados. La incorporación de no-indígenas entre los comanches y los ranqueles en el siglo XIX. Cuicuilco 6 (17): 153-171.

Roulet, F.

1999-2001 De cautivos a aliados: los "Indios Fronterizos" de Mendoza (1780-1806). Xama 12-14: 199-239. INCIHUSA/ CRICYT, Mendoza.

2004 Con la pluma y la palabra. El lado oscuro de las negociaciones de paz entre españoles e indígenas. Revista de Indias LXIV (231): 313-347. CSIC, Madrid, España.

Salomón Tarquini, C.

2006 Santiago Avendaño. El niño que hablaba con el papel. En Vivir entre Dos Mundos. Las Fronteras del Sur de la Argentina. Siglos XVIII Y XIX editado por R. Mandrini Raúl, pp. 119-136. Taurus, Buenos Aires.

Socolow, S. M.

1992 Spanish Captives in Indian Societies: Cultural Contact along the Argentine Frontier 1600-1835. The Hispanic American Historical Review 72 (1): 73-99.

Topolski, J.

1982 Metodología de la Historia. Ediciones Cátedra, Madrid, España.

Villar, D. y J. F. Jiménez

2005 En continuo trato con infieles. Los renegados de la región pampeana centro-oriental durante el último tercio del siglo XVIII. Memoria Americana 13: 151-178.

\section{Archivos y fuentes primarias}

Archivo General de la Nación (AGN), Argentina.

Declaración de José Lorenzo Ferreira Fuerte de El Zanjón, 14 de diciembre de 1767. AGN IX 1-5-3.

Declaración que dio Juan Pascual Zurita en la guardia del Zanjón, 26 de noviembre de 1768. AGN IX 1-5-3.

Declaración de Andrés Rodríguez, Fuerte de San Juan de Chascomús, 20 de febrero de 1781. AGN IX 1-4-3.

Declaración de Pedro Pablo Maldonado, Frontera de Luján, 26 de agosto de 1783. AGN IX 1-4-6. 
Interrogatorio [El Zanjón, 1787]. AGN IX 1-5-3.

Archivo General de la provincia de Santa Fe (AGPSF), Argentina.

Acta del Cabildo de Santa Fe del 25 de junio de 1726.

Archivo General de Indias, Sevilla (AGI).
Buenos Aires, 250. Testimonios de diligencias con los cinco caciques mocoví. Santiago del Estero, junio y julio de 1770.

Charcas 325. Información dada por el procurador de Asunción, 26 de agosto de 1755 .

\section{Notas}

1 Más allá del tecnicismo de considerar si debemos llamar "excautivo" a una persona que había logrado cesar en su condición de cautivo, mantenemos aquí la denominación que aparece en la documentación y bajo la cual utilizamos esos testimonios en la actualidad.

2 Maldonado (2011) ofrece una exhaustiva descripción sobre las características formales de los documentos coloniales.

3 Nos referimos, entre otros, a los trabajos de Areces et. al (1992); Ávila (1994); Lucaioli (2011); Lucaioli y Latini (2014); Mayo (1985); Néspolo (2008); Operé (1997); Ortelli (1999); Roulet (1999-2001); Salomón Tarquini (2006); Socolow (1992); Villar y Jiménez (2005).

4 Declaración que dio Juan Pascual Zurita en la guardia del Zanjón, 26 de noviembre de 1768. AGN IX 1-5-3.

5 Declaración de Pedro Pablo Maldonado, Frontera de Luján, 26 de agosto de 1783. AGN IX 1-4-6.

6 Declaración de Andrés Rodríguez, Fuerte de Chascomús, 20 de febrero de 1781. AGN IX 1-4-3.

7 Carta de Jerónimo Matorras a Carlos III. En Testimonios de diligencias con los cinco caciques mocoví. Santiago del Estero, junio y julio de 1770. AGI, Buenos Aires, 250.

8 Interrogatorio [El Zanjón, 1787]. AGN IX 1-5-3.

9 Muzzopappa y Villalta (2011) han abordado un caso actual en el que se consideran los formulismos utilizados en los documentos estatales.

10 El caso de Cristóbal de Almaraz ha sido analizado por Lucaioli (2011).

11 Las memorias de Santiago Avendaño fueron publicadas por Meinrado Hux (1999).

12 Declaración de Andrés Rodríguez, Fuerte de Chascomús, 20 de febrero de 1781. AGN IX 1-4-3.
13 No discutiremos aquí el hecho de que bajo el rótulo de cautivos se incluía un heterogéneo grupo de desertores, marginales, fugitivos y cautivos propiamente dichos (Nacuzzi 2011; Ortelli 1999; Villar y Jiménez 2005). No siempre estos individuos que regresaban de entre los indios habían estado allí por la fuerza ni su permanencia había sido obligada. No obstante, la convivencia voluntaria con los "indios infieles" constituía una suerte de tabú que invisibilizaba las motivaciones ocultas en estas situaciones.

14 Declaración de Rafael de Holmos, Juan de Mansilla y Pablo Cardozo. En Testimonios de diligencias con los cinco caciques mocoví. Santiago del Estero, junio y julio de 1770. AGI, Buenos Aires, 250.

15 Declaración. En Testimonios de diligencias con los cinco caciques mocoví. Santiago del Estero, junio y julio de 1770. AGI, Buenos Aires, 250.

16 Declaración de Rafael de Holmos, Juan de Mansilla y Pablo Cardozo. En Testimonios de diligencias con los cinco caciques mocoví. Santiago del Estero, junio y julio de 1770. AGI, Buenos Aires, 250.

17 Declaración de Pedro Pablo Maldonado, Frontera de Luján, 26 de agosto de 1783. AGN IX 1-4-6.

18 Información dada por el procurador de Asunción, 26 de agosto de 1755. AGI, Charcas 325.

19 Acta del Cabildo de Santa Fe del 25 de junio de 1726. http://www.santafe.gob.ar/actascabildo/default/ ficha/3790-25_de_Junio_de_1726.

20 Declaración de José Lorenzo Ferreira, Fuerte de El Zanjón, 14 de diciembre de 1767, AGN IX 1-5-3. 
